\title{
Customer Interaction as a Source for Innovation? Evidence from Hybrid Offerings
}

\author{
Mario Schaarschmidt and Gianfranco Walsh
}

\begin{abstract}
The link between customer interaction and innovation has been investigated intensely in relation to different customer-firm interactions (Bartl et al. 2012; Lau et al. 2010), various degrees of innovation (e.g., incremental and radical; Coviello and Joseph 2012), distinct organizational practices and capabilities (Foss et al. 2011), and new services or products (Carbonell et al. 2009; Chen et al. 2011). However, little research addresses customer interactions and their implications for hybrid offerings. Hybrid offerings combine physical products, or goods, and services into innovative solutions, such that they differ from both pure services (e.g., financial, health) and pure manufacturing offerings (e.g., machinery; Gebauer et al. 2011). Hybrid offerings allow goods-oriented firms to capture additional value from the knowledge they possess; understanding the process that leads to innovation in either goods or service components of a hybrid offering thus can help managers recognize when they should stimulate customer interactions. Because extant research has focused on goods or service innovation, not the impact of customer interactions for goods and related service innovations simultaneously, an isolated view has emerged. Yet a firm's integrated ability to offer hybrid offerings often represents a competitive advantage (Ulaga and Reinartz 2011). Therefore, we seek to clarify (1) whether paths that exist in isolation between customer interaction and goods innovation and customer interaction and services innovation remain stable for hybrid offerings and (2) if customer interaction affects one type of innovation, to the detriment of the other. We use primary data from 146 firms and find that customer interaction both benefits goods and service innovation performance in hybrid offerings.
\end{abstract}

References available upon request.

\footnotetext{
M. Schaarschmidt $(\square)$

University of Koblenz-Landau, Mainz, Germany

e-mail: mario.schaarschmidt@uni-koblenz.de

G. Walsh

Friedrich-Schiller-University of Jena, Jena, Germany

e-mail:walsh@uni-jena.de

L. Petruzzellis, R.S. Winer (eds.), Rediscovering the Essentiality of Marketing, Developments in Marketing Science: Proceedings of the Academy of Marketing Science, DOI 10.1007/978-3-319-29877-1_94
} 